\title{
Maximum Power Point Tracking from a Wind Turbine Emulator Using a DC-DC Converter Controlled
}

\author{
Ruihong Yu, Yanqin Li and Jianxian Cai \\ Department of Disaster Prevention Apparatus, Institute of Disaster Prevention \\ East Yanjiao, Sanhe, Hebei, China, 065201 \\ yuruihong97@sina.com
}

\begin{abstract}
Development and utilization of wind energy has become an important part of world sustainable energy development strategy. A control method realizing maximam power point tracking of wind turbine through adjusting the load characteristics was proposed in this article. The power management system based on DC/DOConvertors was designed. The maximum power point tracker (MPPT) extracts maximum power from the wind turbine from cut-in to rated wind velocity by sensing only dc link power. The MPPT step and search algorithm in addition to the DC/DC are simulated using MATLAB-SIMULINK software. The results show that the DC/DC convertors topology can realise the maximum power point tracking control of the wind turbine.
\end{abstract}

Keywords: MPPT algorithm, DC/D \& conyertors, wind turbine system.

\section{Introduction}

Development and utilization of wind ekergy has become an important part of world sustainable energy development'strategy. Wind power generation is the most important form of the development and utilization of wind energy. Wind power generation system can be divided into two categories that the constant speed constant frequency and variable speed constant frequency (VSCF).VSCE wind power generation system divided into two drive modes which is indirect and diyect drive. The direct drive wind power system use the permanent magnet synchronoys generator with low speed to transform the wind generator output power into alternating current which is frequency and constant voltage into the grid. So the system has the advantages of simple structure. It has become one of the main current of wind power generation.

The DC/DC converter is a core part of wind power maximum power point tracking controller.Its dynamic characteristics have an impact on the system. It is based on the theory of nonlinear dynamics system. Reference [1] using periodic switching model analysis of the hybrid dynamic characteristics of DC /DC converters, and study the system's controllability, observability and reachability; Reference [2] study on hybrid control problem of Boost power converter, through the design of hybrid control law for regulating output voltage of the converter; Reference [3] is based on sliding mode observer established hybrid system state model of DC-DC converter. Reference [4] uses the theory of hybrid systems, integration of two order DC-DC converter for hybrid system model; the system stability is analyzed based on the Lyapunov direct method, then put forward a new kind of sliding mode control strategy.

In this context, we will discuss bout the basic knowledge of wind speed in Section 2 and the wind turbine model is proposed in Section 3. In Section 4, the wind turbine emulator 
power electronics is presented. The model of maximum power controller and DC/DC converter is established in Section 5. Finally, the simulation and conclusion is made in the last section.

\section{Basic Knowledge of Wind Speed}

\subsection{The distribution of wind speed}

Numerical distribution model to describe the wind speed are two parameter Weibull distribution, three parameter Weibull distributions and Rayleigh distribution. Among them, two parameter Weibull curve fits the rule of wind speed distribution. It belongs to the unimodal normal distribution function, the probability density function:

$$
f(v)=\frac{k}{c}\left(\frac{v}{c}\right)^{k-1} e^{-\left(\frac{v}{c}\right)^{k}}
$$

Where the $\mathrm{K}$ is shape parameter; $\mathrm{C}$ is scale parameter. In the practical application, according to statistical data to determine the Weibull parameters of wind speed, then calculating the average wind speed $\mathrm{v}$ and standard deviation of

The expression for the follow function:

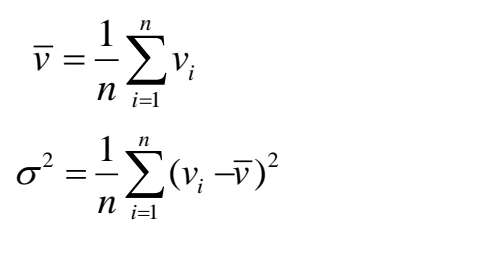

Based on the mean and variance of the Weibull distribution approximation formula, we can get:

Where

$$
\begin{aligned}
& \bar{v}=\int_{0}^{\infty} v f(v) d v=c \Gamma\left(1+\frac{1}{k}\right) \\
& \Gamma(a)=\int_{0}^{\infty} t^{a-1} e^{-t} d t
\end{aligned}
$$

\subsection{The related factors of Rated wind speed}

At present, the method for determining the rated wind speed can be expressed as

$$
v_{t}=c\left(\frac{k+2}{k}\right)^{\frac{1}{k}}
$$

\subsubsection{The relationship between the rated speed and rated power}

The rated power of the wind power generator is:

$$
P=\frac{1}{2} \rho A v_{t}^{3} C_{p}
$$

Where, the $\rho$ is air density; A is the rotor rotational area's is the power coefficient. The formula (7) shows that the rated power and rated wind speed is proportional to 3 times, it also related to the local density of the air, the wind area and power coefficient 


\subsubsection{The relationship between wind speed and the rotor diameter}

The Rated power of wind generator is

$$
P\left(v_{t}\right)=\frac{1}{8} \eta \rho \pi d v_{t}^{3}
$$

Where, the $\eta$ is efficiency, and $d$ is rotor diameter.

The relationship between the rotor diameter and the rated wind speed is:

$$
d=2 \sqrt{\frac{2 P\left(v_{t}\right)}{\pi \rho C_{p} v_{t}^{3}}}
$$

The formula (9) shows that appropriately increasing the rated wind speed can reduce the rotor diameter. But with the rotor diameter increases, the weight of hub will increase.

\section{Wind Turbine Model}

The model of the WT employed in the system includes the nonlinearities ahd dynamics of a realistic wind turbine. In this research, the dynamics of the furling action and rotor are incorporated.

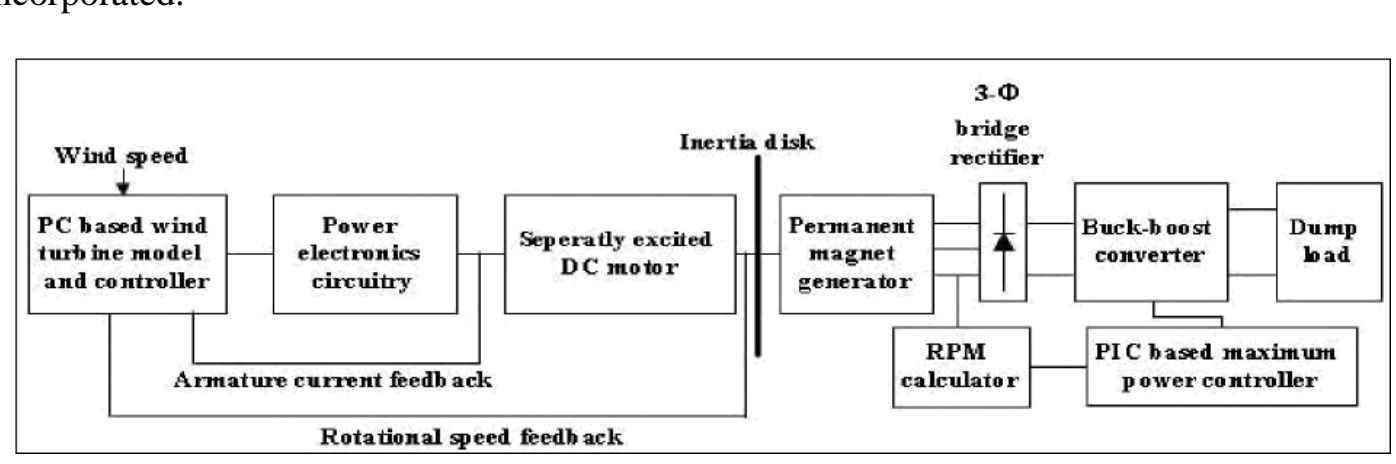

Figure 1. Bipck diagram of the Wind Turbine Emulator system

Rather an inertia disk was added to the system to represent the inertia of the wind turbine rotor. A wind turbine can be characterized by the non-dimensional curve of power coefficient $C_{p}$ as a function of Tip $\$$ Speed Ratio (TSR) $\lambda$, where, $\lambda$ is given in terms of rotor speed, $\omega_{m}$, $(\mathrm{rad} / \mathrm{s})$, wind speed, $f(\mathrm{~m} / \mathrm{s})$, and rotor radius, $R(m)$ as

$$
\lambda=\frac{R * \omega_{m}}{v}
$$

The relationship between $C_{p}$ and $\lambda$ is typical and can be approximated by a quadratic equation. In this research, the curve was obtained from the literature [5]. A model for $C_{p}$ as a function of $\lambda$ was calculated and the curve generated by the approximate model and the actual data are presented in Figure 2(a). Statistical analysis showed that the $R^{2}$ value of the model was $99.8 \%$ and goodness of fit was less than 0.0001 , which shows that the predicted model for $C_{p}$ with the fitted coefficients is acceptable.

The resulting equation was found to be:

$$
C_{p}(\lambda)=000056 \lambda^{4}-0.005 \lambda^{3}+0.105 \lambda^{2}-0.4 \lambda+0.25
$$


The curve between wind speed and furling angle was derived from published data [6, 7]. An approximate model was used to determine the relation between wind speed and furling angle and found that a fifth order model is sufficient to represent the relationship. The actual data and approximated model curve are represented in Figure 2(b).

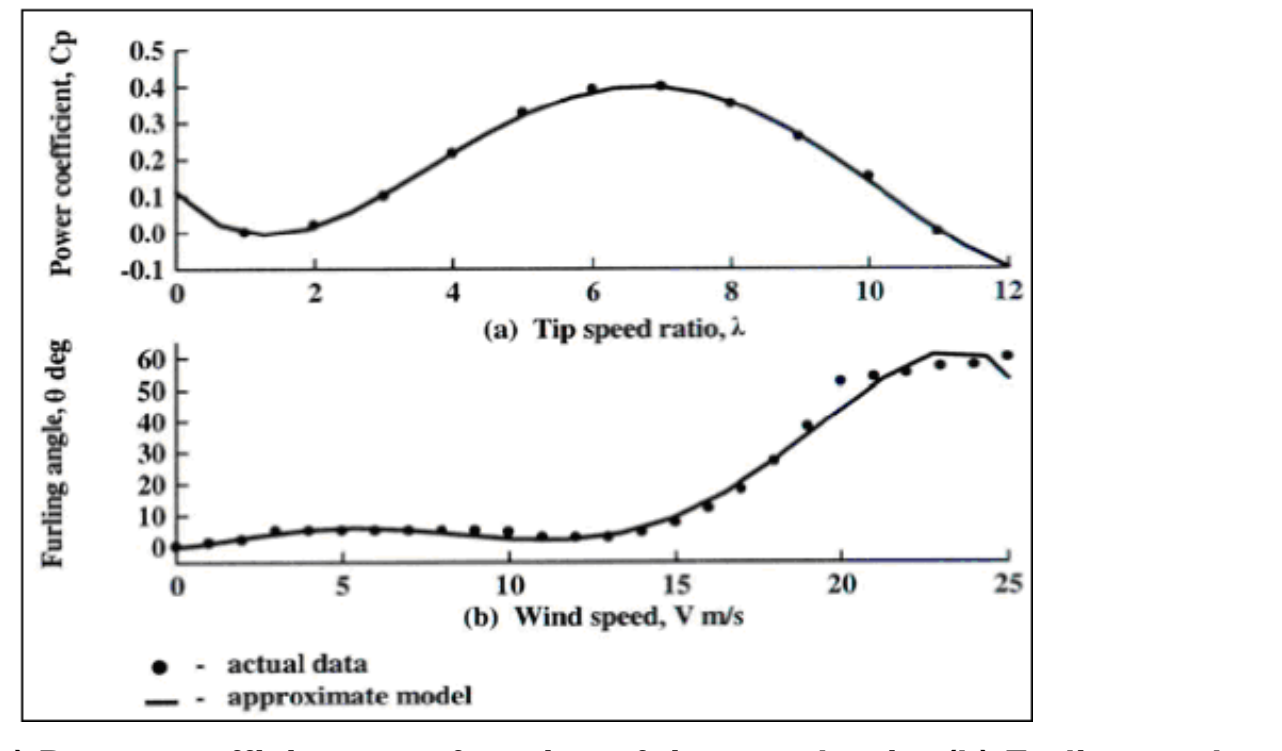

Figure 2. (a) Power coefficient as a function of tip-speed ratio; (b) Furling angle versus wind speed

\section{Wind Turbine Emulator Power Electronics}

To represent the WT rotor, a separately exc ted DC motor was used because DC drive can operate more accurately at low speeds, thus ensuring accurate emulation at low wind speeds. The PC based controller triggers the phase controlled relay through a LabMaster I/O board. An inertia disk was coupled to the symehronous generator. It represents the inertia of a real wind turbine rotor. A complete schematic of the wind turbine section of the emulator is shown in Figure 3 [8, 9].

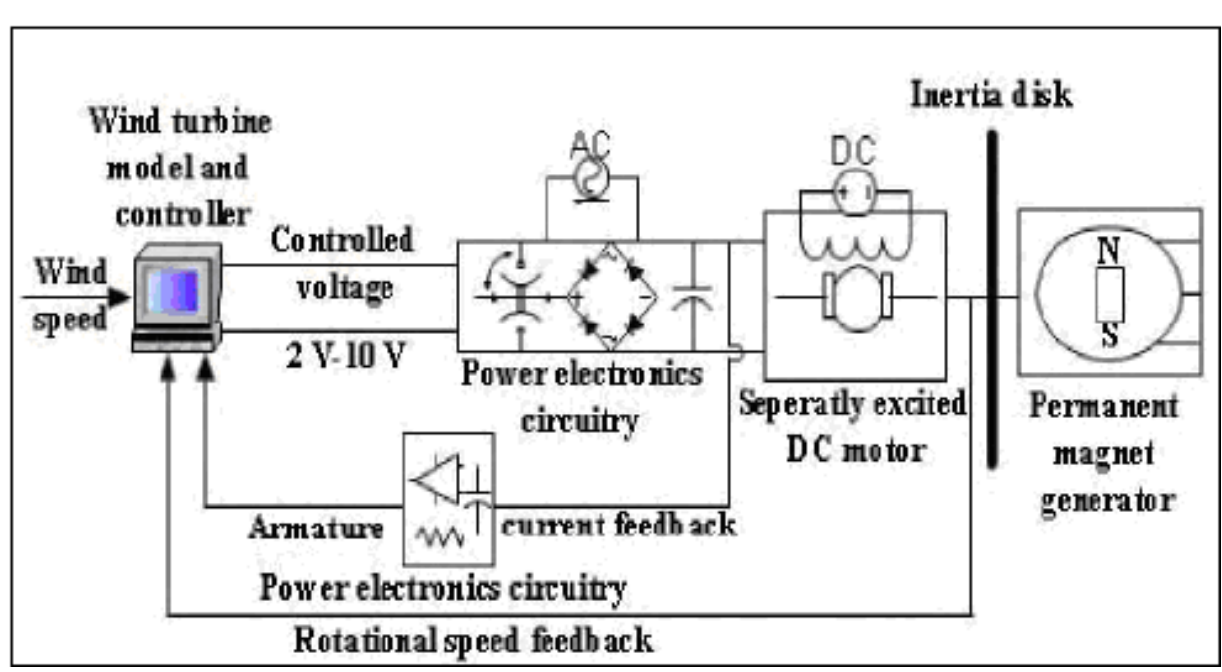

Figure 3. Schematic of the wind turbine section of the emulator 


\section{Maximum Power Controller and DC/DC Converter Controller}

According to the formula 7, curve as shown in Figure 4 for the wind turbine output power $\mathrm{P}$ and speed $\mathrm{w}$ under different wind speeds. Each wind speed has a maximum power point. These maximum power points are connected by a curve. Then we can get the maximum power curve of wind turbine. At each point of the maximum power curve, the changes in wind turbine output power relative to change of the speed is zero.

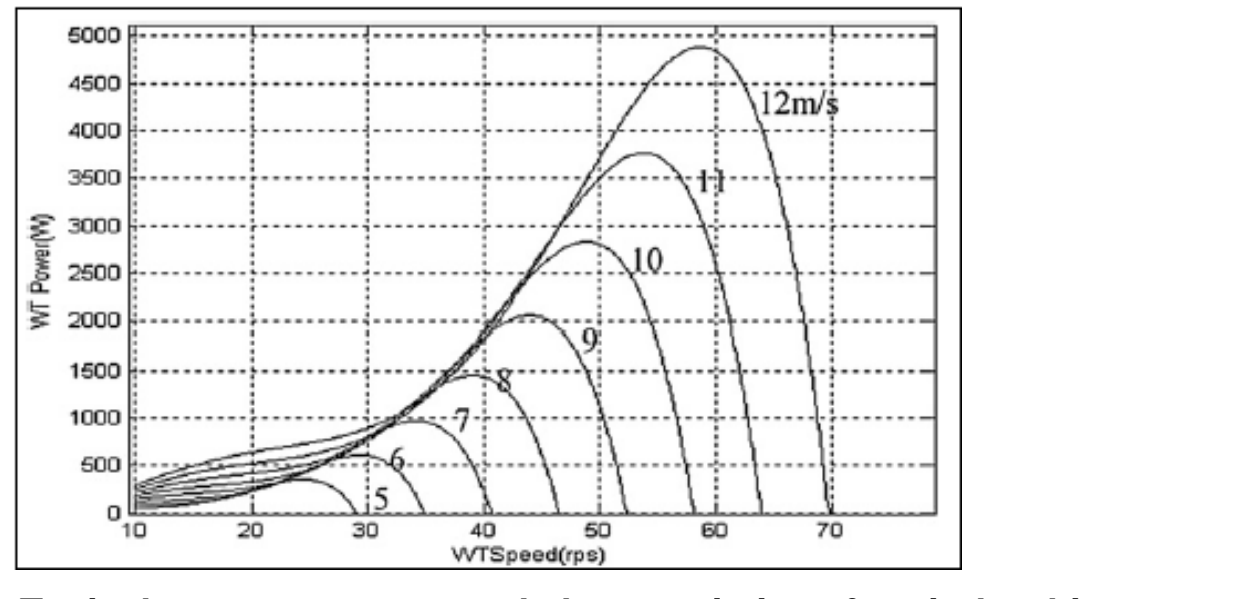

Figure 4. Typical power versus speed characteristics of a wind turbine

At this time, the wind turbine output power can be expressed as

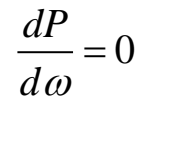

From Figure 4 we can also know, throulgh the mediation of the rotating speed of the wind wheel can mediate the maximum outpat poyver. In order to achieve this goal, we have through the mediation of DC converter to change the load characteristics of wind turbine, and mediation rotate speed of wind Theh the wind turbine output power can track the maximum power. This is based on the circuit theory: when the external load equivalent impedance and power source internal impedance conjugate, external load can get the maximum output power [10-12]. The main circuit of the DC converter is composed of inductor, switch, rectifier diode and a filter capacitor which is a series in the loop. It transforms the impedance by controlling the duty ratio. Not only it can complete the voltage transformation, but can change input impedance of the DC converter [13-16].

The inpu veltage, output voltage and the duty ratio of the DC converter will be express in following ormula:

$$
D=1-\frac{V_{\text {in }}}{V_{\text {out }}}
$$

Where, the $D$ is duty ratio of the DC converter, $V_{\text {in }}$ is input voltage of the DC converter, and $V_{\text {out }}$ is output voltage of the DC converter.

We transform the formula (13) as below:

$$
\frac{d P}{d \omega}=\frac{d P}{d D} \frac{d D}{d V_{i n}} \frac{d V_{i n}}{d \omega_{1}} \frac{d \omega_{1}}{d \omega}=0
$$

Where, the $\omega_{1}$ is the angular velocity of the generator. 
At the same time, the following relationship has established:

$$
\frac{d D}{d V_{\text {in }}}=-\frac{1}{V_{\text {out }}} \neq 0
$$

There is proportional relationship between the input voltage of DC converter and generator EMF, therefore, we can get:

$$
\frac{d V_{i n}}{d \omega_{1}} \neq 0
$$

From the formula (14) to (16), we can get:

$$
\frac{d P}{d \omega}=\frac{d P}{d D}=0
$$

So, we can prove the theory that through the mediation of DC converter duty ratio to achieve the maximum power tracking control of the wind turbine.

In order to extract the maximum power, an optimum TSR control was selected.The actual TSR of the wind turbine was compared with the optimum TSR and the microcontroller controlled the duty ratio of the buck-boost converter in orden to control the effective dump load connected to the system. The basic structure of the maximum power extraetor is shown in Figure 5 and Figure 6.

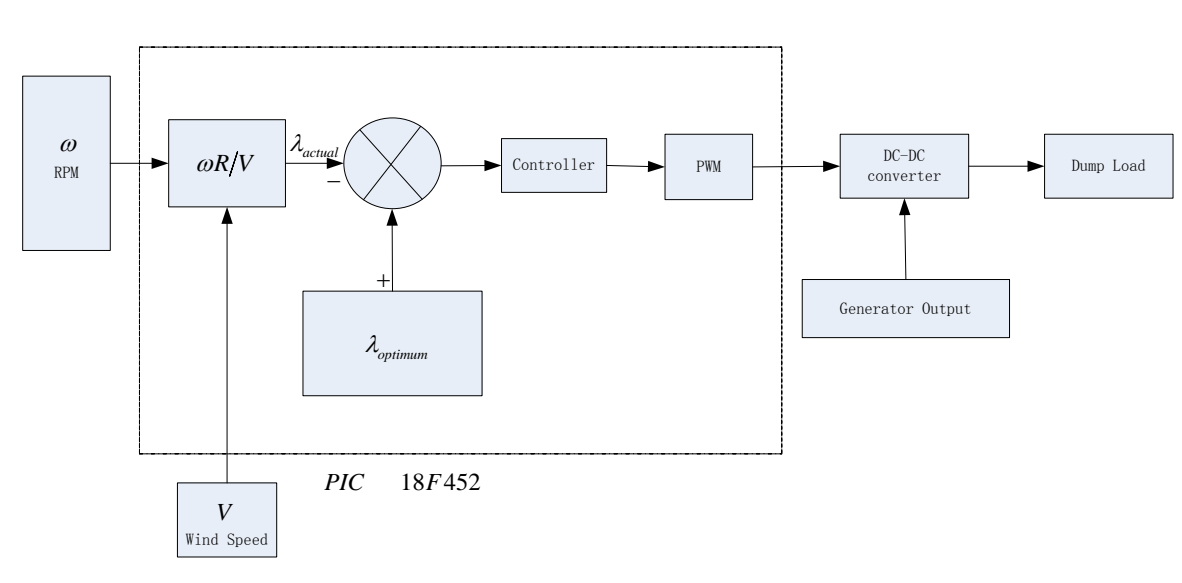

Figure 5. Structure of the maximum power point extractor

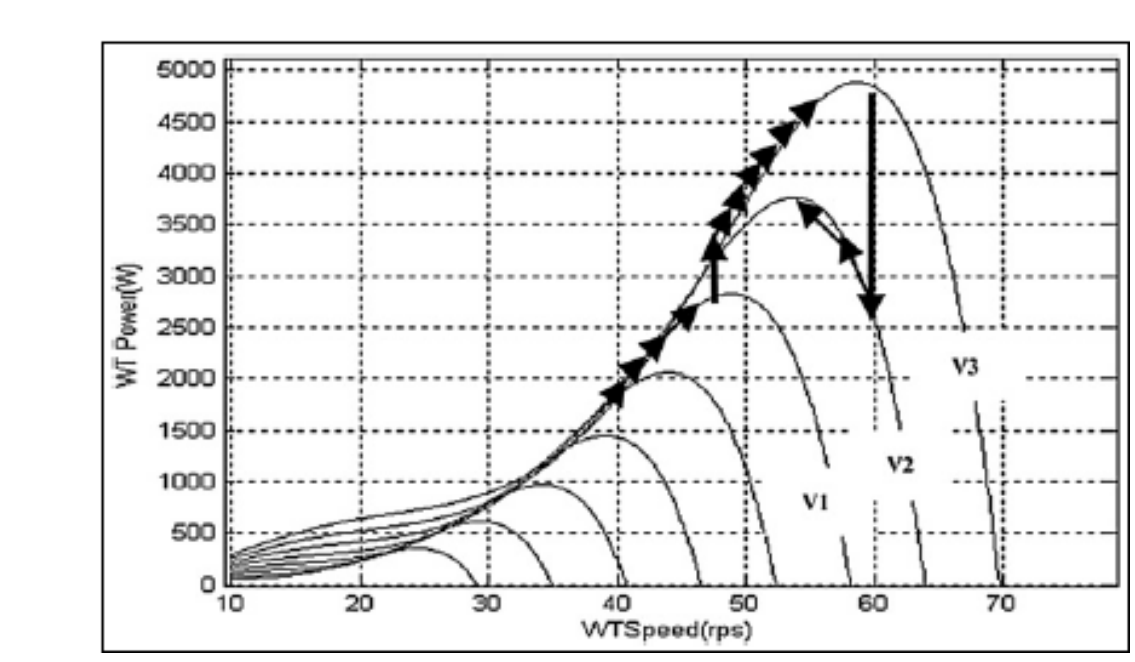

Figure 6. Maximum power tracking process 


\section{Simulation}

The MATLAB Simulink model of the Wind Turbine Emulator system is first presented. Simulation results with the MPPT in addition to the comments will then be given for two wind speeds 6,8 and $10 \mathrm{~m} / \mathrm{s}$. The electric machine and the dc-to-dc converter parameters are given in Appendix. It is noticed from Figure 10 that the controller is able to search for maximum power and keep the power coefficient of the wind turbine is much closed.

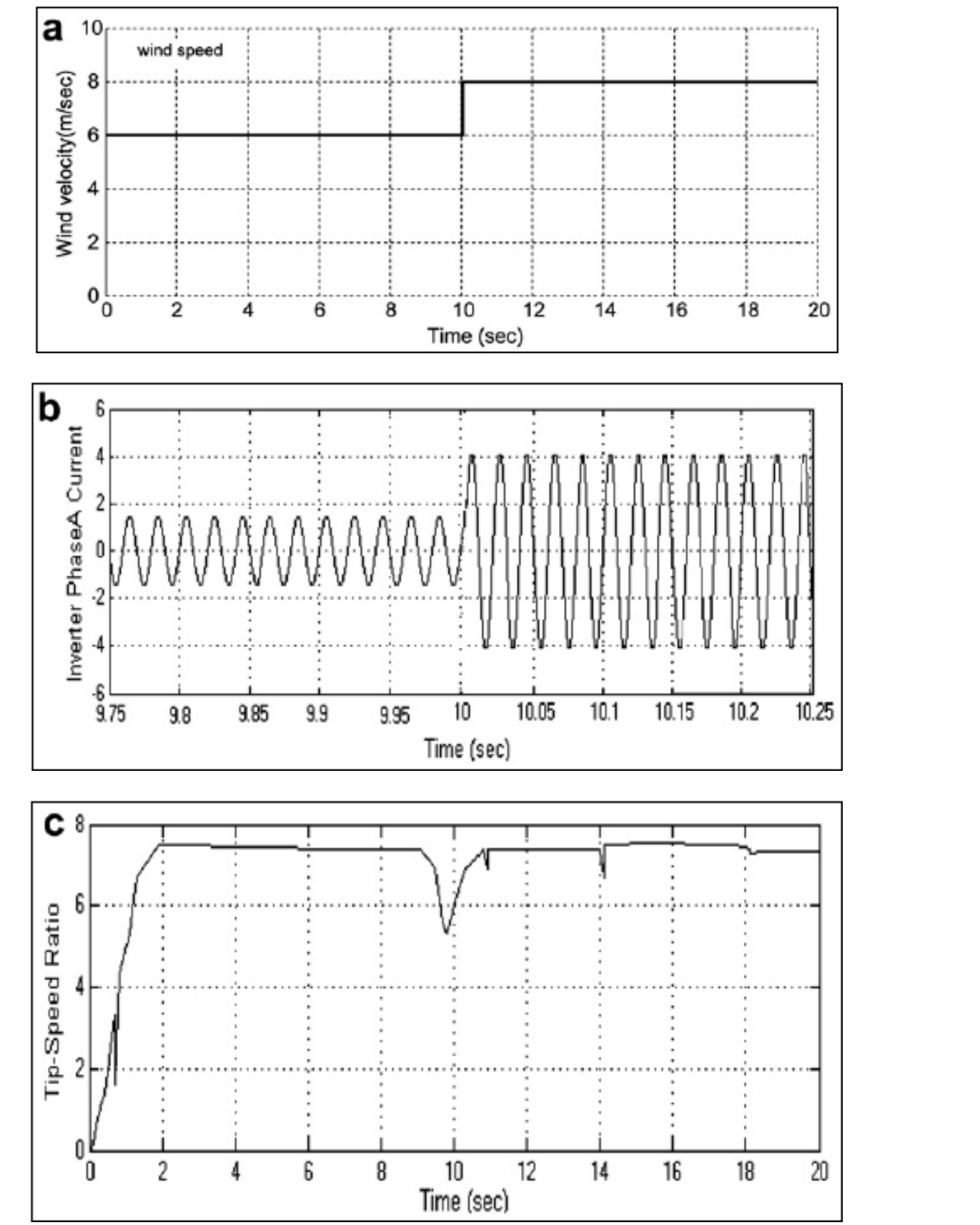

Figure 7. MPPT for a step change in wind speed 
International Journal of Control and Automation Vol.7, No.1 (2014)
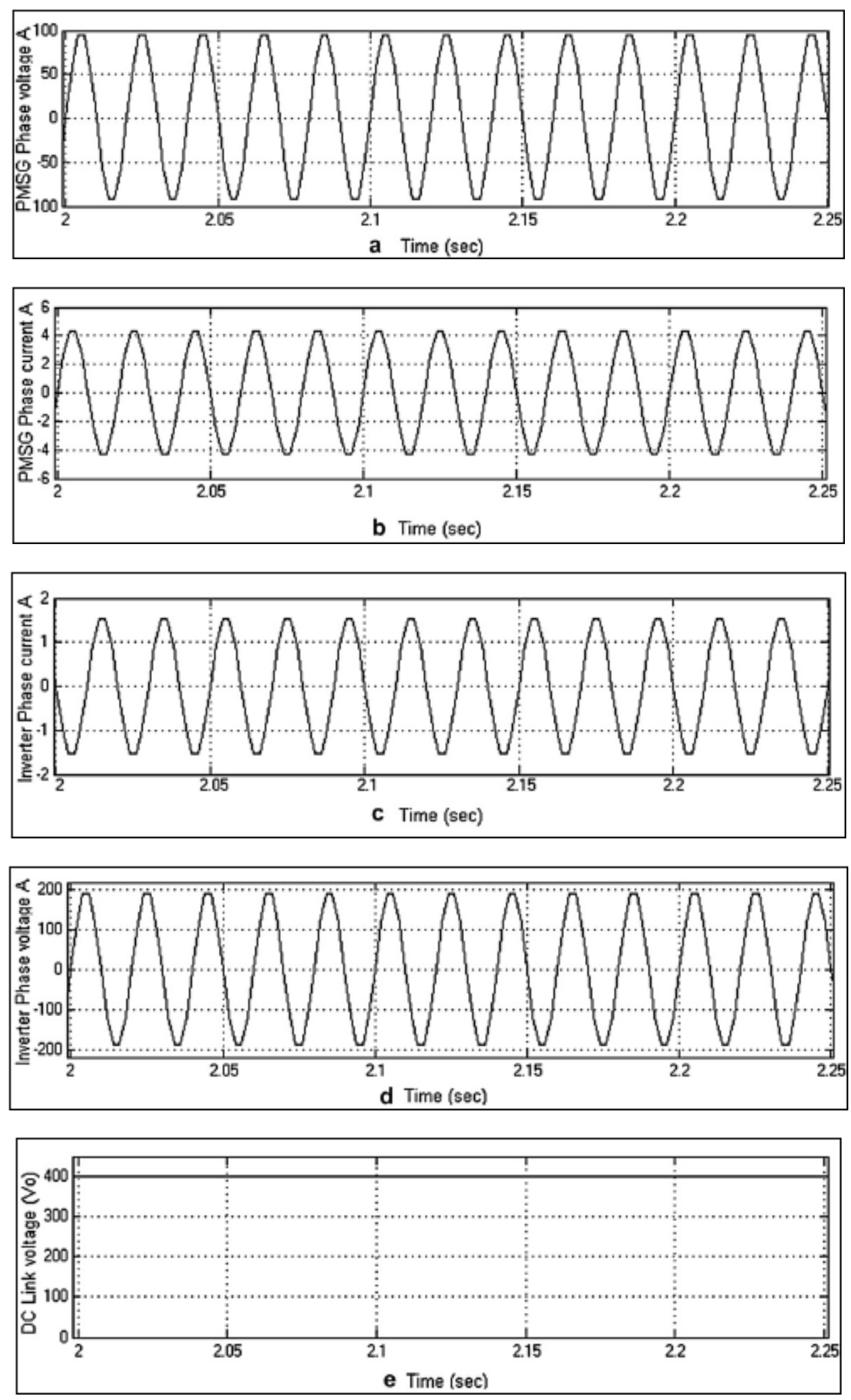

Figure 8. Simulation results for wind speed $6 \mathrm{~m} / \mathrm{s}$ 

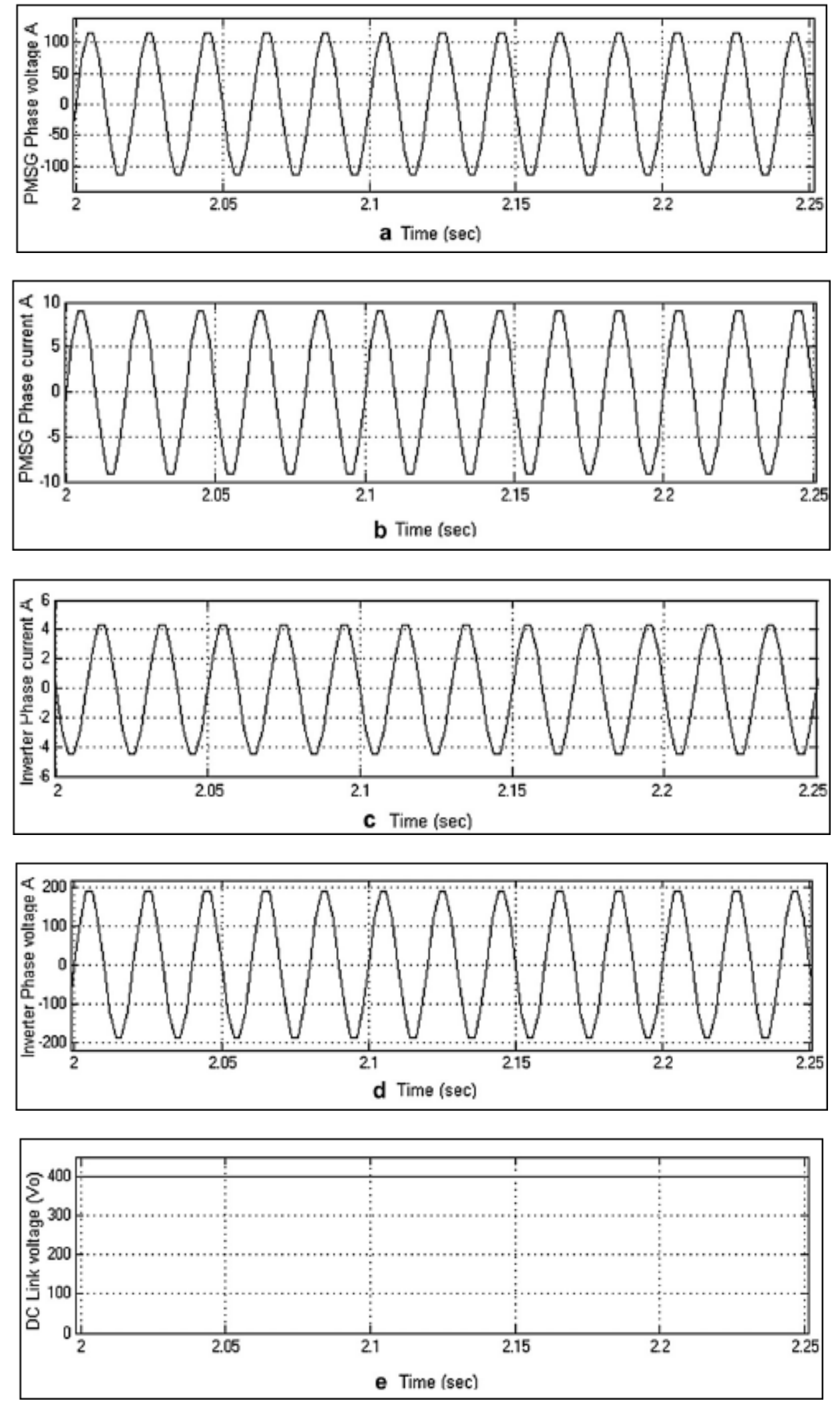

Figure 9. Simulation results for wind speed $8 \mathrm{~m} / \mathrm{s}$ 

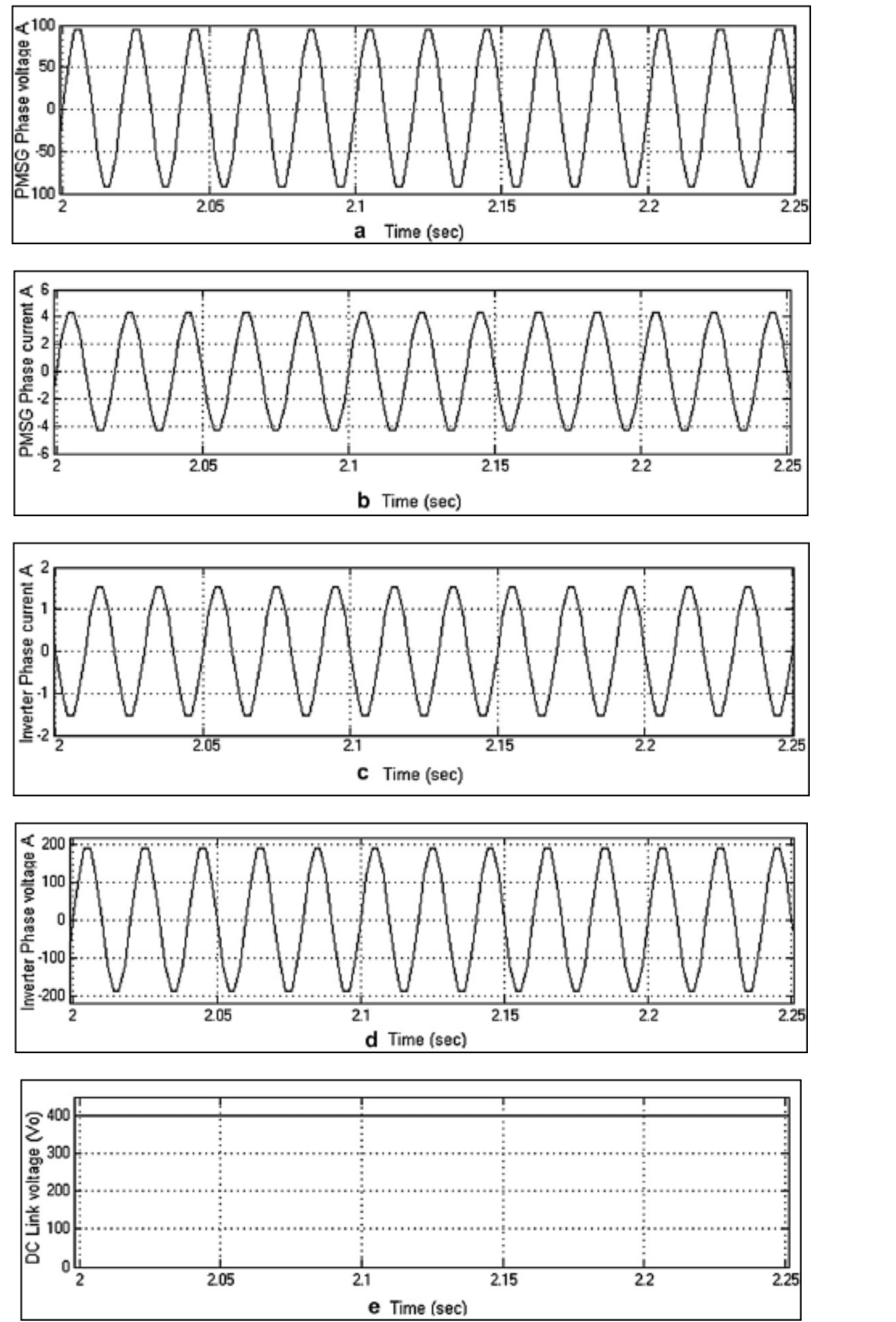

Figure 10. Simulation results for wind speed $10 \mathrm{~m} / \mathrm{s}$ 


\section{Conclusions}

The system maximum energy capture characteristics are simulated in Matlab / Simulink environment. The simulation results show that, by controlling the DC converter can realize the goals that wind turbine output power tracking the maximum theoretical power. Wind turbine power coefficient and duty ratio has remained near the optimal value in system design. This has fully demonstrated the correctness of the wind power energy management system and the feasibility of control strategy of maximum power point tracking in this article.

\section{Acknowledgements}

The authors also want to give their thanks to the following funds for their support:

Special Fund of Fundamental Scientific Research Business Expense for Higher School of Central ${ }^{\bullet}$ Government (Projects for young teachers) ZY20120209;

Teachers' Scientific Research Fund of China Earthquake Administration 20120106.

\section{References}

[1] A. Kavitha and G. Uma, "Experimental verification of hop bifureation in DC- DC lud converter", IEEE Transactions on Power Electronics, vol. 23, no. 6, (2008), pp. 2878 - 2883.

[2] C. Sreekumar and V. Agarwal, "A hybrid control algorithm for voltage regulation in DC- DC boost converter", IEEE Transactions on Industrial Electronics, vol 55 , no. 6, (2008), pp, 2530 -2538.

[3] M. O. Friedrich, N. Jason, P. Steve, et al., "MPC of switehing in a boost converter using a hybrid state model with a sliding mode observer", IEEE Transactions on/Industrial Electronics, vol. 56, no. 9, (2009), pp. 3453 3466.

[4] A. G. Beccuti, G. Papafotiou and M. Morari, "Optimal control of the boost estimation for inferential DC/ Converter", Proceedings of the 44th IEER Conference on Decision and Control, and the European Control Conference, (2005), pp. 4457-4462.

[5] E. Muljadi, T. Forsyuth and C. P. Butterfierd, "Soft stall control versus furling control for small wind turbine power regulation", Wind power '98. Bakersfield, California, (1998), pp. 5-14.

[6] D. Corbus and D. Prascher, "Analysis ahd comparison of test results from the small wind research turbine test project", AIAA Aerospace Sciences Meeting and Exhibit, Reno, Nevada, (2005).

[7] A. J. Eggers Jr., K. Chaney, W. E. Holley, H. Ashley, H. J. Green and J. Sencenbaugh, "Modeling of Yawing and furling behavior of Smaly wind turbines? The American Institute of Aeronautics and Astronautics (AIAA) and the American Society of Mechanical Engineers, (2000), pp. 1-11.

[8] J. T. Bialasiewicz, "Furling control førsmall wind turbine power regulation", ISIE '03, vol. 2, (2003) June, pp. 804-809.

[9] H. Zhang, C. Saudemont, B. Robyns, et al., "Stability analy-sis on the DC power distribution system of more electric aircraft", Proceedings ol 13th Power Electronics and Motion Control Conference, New York: IEEE, vol. $8,(\mathbf{2 0 0 8})$, pp. 1523-1528.

[10] C. H. Rivetta, A. Emadi, G. A. Williamson, et al., "Analysis andcontrol of a buck DC-DC converter operating with constant powefload in sea and undersea vehicles", IEEE Transactions on IndustrialElectronics, vol. 42, no. 2, (2006), pp-5s9-572.

[11] N. Yamamura, M. Ishida And T. Hori, "A simple wind power generating system withpermanent magnet type synchronou generator", Power Electronics and DriveSystems (PEDS), vol. 2, (1999), pp. 49-54.

[12] E. Koutroulis and K. Kalaitzakis, "Design of a maximum power tracking system forwind-energy-conversion applications", IEEE Transactions on Industrial Electronics, vol. 53, no. 2, (2006), pp. 86-94.

[13] S. H. Song, S. Kang and N. Hahm, "Implementation and control of grid connected AC-DC-AC power converter for variable speed wind energy conversion system”, In: Proceedings of IEEE APEC'03, vol. 1, (2003) February, pp. 154-158.

[14] A. Koyanagi, H. Nakamura, M. Kobayashi, Y. Suzuki and R. Shimada, "Study on maximum power point tracking of wind turbine generator using a flywheel”, In: Proceedings of IEEE PCC'02, vol. 1, (2002) April, pp. 322-327.

[15] R. Pena, J. C. Clare and G. M. Asher, "Doubly fed induction generator using back-to-back PWM converters and its application to variable-speed wind-energy generation", IEE Proc Electric Power Applications, vol. 143, (1996), pp. 231-241.

[16] E. Koutroulis and K. Kalaitzakis, "Design of a maximum powertracking system for wind-energy-conversion applications", IEEE Trans. Ind Electron., vol. 53, no. 12, (2006) April, pp. 486-494. 


\section{Authors}

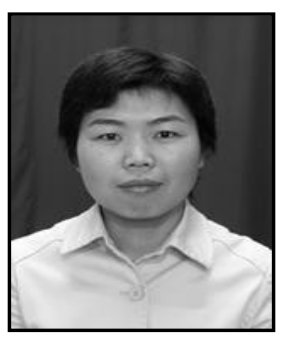

Ruihong Yu. She received her B.Sc. in electrical engineering and automation (2002) from School of Electrical Engineering of Shandong University, China. And she received her M.Sc. in electric power system and automation (2006) from Xihua University, China. Now she is a Lecture with the Department of Disaster Prevention Instrument, Institute of Disaster Prevention, Hebei, CN. Her current research interests include automatic control, detection technology and automatic equipment.

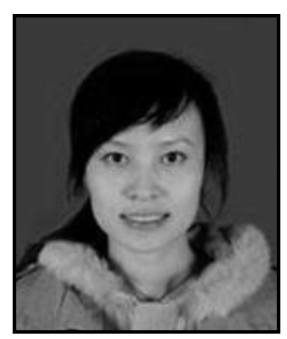

Yanqin Li. She received her B.Sc. in electrical information engineering (2004) from department of Electrical Engineering of Taiyuan Science Institute, China. She receeived her M.Sc. in electricity and system (2007) from Taiyuan University of technology, China. Now she is a Lecture with the Department of Disaster Prevention Instrument, Institute of Disaster Prevention, Hebei, CN. Her current research interest is blind signal processing.

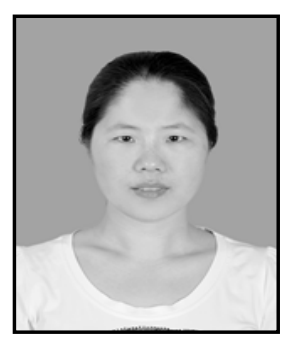

Jianxian Cai. She received her M.Sc. in control theory and control engineering (2003) from Ranshan Univetsity, China, and received $\mathrm{PhD}$ in pattern recognition and artifieial intelligence (2010) from Beijing University of Technology, China. Currently, she is associate professor with the Department of Disaster Prevention Instrument, Institute of Disaster Prefention, Heben, CN. Her main research interests include automatic control, robot intelligent control and machine learning.

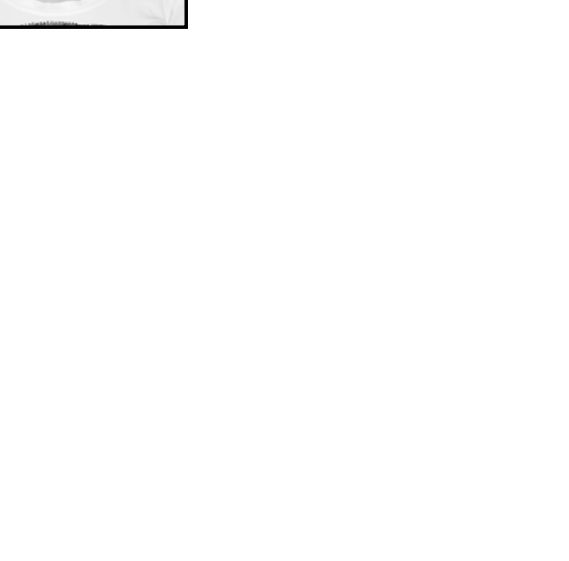

